\title{
Effect of Pragmatic Instruction on Sustainable Development of Pragmatic Awareness
}

\author{
Vahid Rafieyan (Corresponding author) \\ School of Educational Studies, Universiti Sains Malaysia (USM) \\ PO Box 11800, Penang, Malaysia \\ E-mail: honeyyear@yahoo.com \\ Maryam Sharafi-Nejad \\ School of Educational Studies, Universiti Sains Malaysia (USM) \\ PO Box 11800, Penang, Malaysia \\ E-mail:msn12_edu085@student.usm.my \\ Lin Siew Eng \\ School of Educational Studies, Universiti Sains Malaysia (USM) \\ PO Box 11800, Penang, Malaysia \\ E-mail: selin@usm.my
}

Received: Feb. 9, 2014 Accepted: February 26, 2014 Published: February 27, 2014

doi:10.5296/jse.v4i1.5088

URL: http://dx.doi.org/10.5296/jse.v4i1.5088

\begin{abstract}
Effective cross-cultural communication is supposed to require awareness of target language pragmatic features. However, inadequate attention is paid to the development of pragmatic awareness in foreign language classrooms. To examine the actual effect of pragmatic instruction on the development and sustainability of pragmatic awareness in foreign language learners, the current study adopted an experimental design by conducting eight intervention sessions on 60 Iranian senior undergraduate learners of English as a Foreign Language at a university in Iran and three administration of a multiple choice pragmatic awareness test
\end{abstract}




\section{Macrothink}

immediately before, immediately after, and two months following the intervention. The results of the repeated measures analysis of variance revealed that pragmatic instruction had a marked effect on the development but not sustainability of pragmatic awareness in English as Foreign Language learners. The pedagogical implications of the findings suggested the inclusion of pragmatic instruction in foreign language classrooms.

Keywords: Cross-cultural Communication, Metapragmatic Explanation, Pragmatic Awareness, Sustainable Development 


\section{Introduction}

Effective cross-cultural communication requires not only knowledge of linguistic competence but also knowledge of pragmatic competence (Jung, 2001). Being pragmatically competent means being able to comprehend and produce a communicative act which often includes one's knowledge about the social distance, social status between the interlocutors involved, the cultural knowledge such as politeness, and the explicit and implicit linguistic knowledge (Kasper, 1997) which presupposes pragmatic awareness defined as "conscious, reflective, explicit knowledge about pragmatics", that is, "knowledge of those rules and conventions underlying appropriate language use in particular communication situations and on the part of members of specific speech community" (Alcon Soler \& Safont Jorda, 2008: 193).

Therefore, unless language learners are provided with explicit sociolinguistic and sociocultural information of the target language (pragmatic awareness), they will experience great difficulties in understanding target language sociolinguistic implications and sociocultural values which affect cross-cultural communication (Safont Jorda, 2005). Furthermore, the examination of language learners' pragmatic awareness can lead to inferences about their pragmatic comprehension ability as well as discovering linguistic factors which contribute to the provision of conditions required for understanding pragmatic meanings since in contrast to native speakers, who may not need to recognize speech act type consciously, foreign language learners' attention to pragmatic issues seems to play a crucial role in developing pragmatic competence (Alcon Soler \& Safont Jorda, 2008).

This has raised the need for developing pragmatic awareness in language learners (Safont Jorda, 2005; Alcon Soler \& Safont Jorda, 2008). However, despite the crucial role of awareness of target language pragmatic features in effective cross-cultural communication, it continues to take a back seat to grammar in classroom practices (Bella, 2012) and teachers in English as Foreign Language contexts focus dominantly on the grammatical aspects of the target language and do not pay adequate attention to the pragmatic features of the target language (Al Falasi, 2007; Farashaiyan \& Tan, 2012). Furthermore; textbooks, which are the major and maybe even the mere source of providing target language exposure in a foreign language context (Richards, 2005), either do not present the pragmatic features of the target language community or contain conversational models which are not naturally evident in the target language instruction (Vellenga, 2004; Martinez-Flor, 2008; Nguyen, 2011).

Given the significant role of awareness of target language pragmatic features in developing pragmatic competence in language learners and enabling them to communicate effectively in cross-cultural contexts, the present study seeks to investigate the effect of pragmatic instruction on developing and sustaining awareness of target language pragmatic features in learners of English as a Foreign Language, that is, whether pragmatic instruction contributes to language learners' awareness of target language pragmatic features and whether this awareness can be retained by them for a period of time following pragmatic instruction. More specifically the research questions to be addressed in this study are:

1. To what extent does pragmatic instruction affect the development of pragmatic awareness? 
2. To what extent does pragmatic instruction affect the sustainability of pragmatic awareness?

Accordingly the hypotheses are:

1. Pragmatic instruction has a significant effect on the development of pragmatic awareness.

2. Pragmatic instruction has a significant effect on the sustainability of pragmatic awareness.

\section{Literature Review}

It has been noted many times that research in interlanguage pragmatics has predominantly been contrastive rather than developmental (Bardovi-Harlig, 1999; Rose, 2000; Kasper \& Rose, 2002). It was only since Kasper and Schmidt's (1996) call for more research into the development of pragmatic competence that the focus of studies turned to the developmental aspect of pragmatic competence. However, although these investigations have provided insights into the development stages involved in the evolution of pragmatic production and comprehension, only a rather limited number of studies have examined the development of pragmatic awareness (e.g. Bardovi-Harlig \& Dornyei, 1998; Matsumura, 2001; Matsumura, 2003; Takahashi, 2005, Schauer, 2006; Matsumura, 2007; Bella, 2012).

In one study, Matsumura (2001) explored the impact of the target language learning environment on the development of language learners' pragmatic awareness. Participants in the study consisted of two groups including 97 Japanese learners of English on an academic exchange program at a university in Canada and 102 Japanese learners of English at a university in Japan. A multiple choice questionnaire focusing on advice giving was used to measure language learners' pragmatic awareness. The findings revealed that the developmental change was observed only among the study abroad language learners suggesting that living and studying in the target speech community had a positive impact on the development of language learners' pragmatic awareness.

Matsumura (2003) conducted another study to examine the effect of target language proficiency and exposure to target language on the development of language learners' pragmatic awareness. Participants in the study consisted of 187 Japanese learners of English on an eight-month academic exchange program at a university in Canada. Pragmatic awareness was measured using a multiple choice questionnaire focusing on offering advice. English proficiency was also measured using language learners' TOEFL marks. Amount of exposure to English was obtained through a self-report questionnaire. The findings revealed that amount of target language exposure has potential to account for the development of pragmatic awareness.

In another study, Takahashi (2005) investigated the effect of two individual difference variables including motivation and language proficiency on language learners' pragmalinguistic awareness. Participants in the study consisted of 80 Japanese learners of English as a Foreign Language at a college in Japan. Data for the study were collected through a motivation questionnaire, a language proficiency test, and an awareness 
retrospection questionnaire. The study found that language learners' motivation but not their language proficiency had a significant effect on the development of their pragmalinguistic awareness.

Schauer (2006) was the other researcher who explored the effect of learning environment on the development of pragmatic awareness in language learners. Two participant groups consisting of 16 German learners of English enrolled at a university in England and 17 German learners of English at a higher education institution in Germany participated in the study. Data for the study were elicited using the combined video-and-questionnaire instrument developed by Bardovi-Harlig and Dornyei (1998). The study revealed that learning environment plays a substantial role in priming language learners' pragmatic awareness.

Following his previous studies, Matsumura (2007) explored the aftereffects of study abroad on language learners' pragmatic awareness. Participants in the study consisted of 15 Japanese learners of English on an eight-month academic exchange program at a university in Canada. Data for the study were collected using a multiple choice questionnaire measuring preference for offering advice three times after language learners' return to Japan and a retrospective group interview to explore why (if any) change in pragmatic awareness occurred. The results of the study suggested that language learners' pragmatic awareness gradually diverged from that of native speakers of English.

Most recently, Bella (2012) investigated the effect of length of residence in the target community on the development of pragmatic awareness in language learners. Two groups of participants with differing lengths of residence in Greece, one group with 1.6 years mean length of residence and the other group with 3 years mean length of residence, participated in the study. The instrument for data collection was the contextualized pragmatic and grammatical judgment test developed by Bardovi-Harlig and Dornyei (1998). The findings of the study revealed that increase in length of residence does not result in increase in pragmatic awareness.

The developmental studies over pragmatic awareness conducted so far have mostly investigated the influential role of some variables such as target language proficiency, motivation, exposure to sociolinguistic and sociocultural features of the target language community, learning environment, and length of residence in the target language culture. However, there is a dearth of research on the effect of teaching target language pragmatic features on the development of pragmatic awareness. Therefore, the current study follows an experimental research design to make up for the insufficiency of acquisitional research in the domain of pragmatic awareness.

\section{Methodology}

\subsection{Participants}

The participants of the study consisted of 60 Iranian learners of English as a Foreign Language. They were all at the last year of their undergraduate studies at the Islamic Azad University of Abadan in Iran. Therefore, they were supposed to have an adequate level of 
linguistic proficiency. Among the participants, 22 were males and 38 were females. Their ages ranged from 22 to 28 with a mean age of 24.2. Besides the 60 focal participants, 20 British native speakers who were working at petrochemical companies in Mahshahr city in Iran at the time of data collection were also included in the study to provide the baseline data for the appropriate answers to the test used in the current study.

\subsection{Instrument}

Data were collected through a multiple choice test consisting of 12 scenarios that were thought to occur in everyday university life and four response choices for each scenario which included direct advice (i.e. the use of 'should' without hedging), hedged advice (i.e. the use of lexical hedging like 'maybe', 'I think'), indirect comments with no advice, and opting out to measure preference for a particular type of speech act when offering advice to individuals of different social status. Each scenario represented one of three social status variables: higher status (a professor), status equal (a classmate), and lower status (a first-year university student). Four scenarios were provided for each social status value. The test was adopted from the test developed and used in previous studies by Matsumura $(2001,2003$, 2007).

\subsection{Instructional Materials}

Materials for the study consisted of Top Notch Books and Top Notch TV Video Programs. Top Notch Books are a dynamic six-level course for international students. Carefully exposing language learners to authentic, natural English, both receptively and productively, Top Notch Books help language learners develop a cultural fluency by creating an awareness of the varied rules across cultures for: politeness, greetings and introductions, appropriateness of dress in different settings, conversation do's and taboos, table manners, and other similar issues. Top Notch TV Video Programs also offer TV-style situation comedies that reintroduce language from each Top Notch unit, plus authentic unrehearsed interviews with English speakers from around the world (Saslow \& Ascher, 2010).

\subsection{Procedure}

At the first week of the first semester of the academic year 2013/2014, pragmatic awareness test was administered to the language learners participating in the study. Participants were instructed to play a role as addressers to the three types of individuals in various advice-giving situations. The week following the test, the participants took part in consciousness-raising pragmatic instruction using metapragmatic explanation of the culture-specific utterances and behaviors contained in Top Notch books and videos. The instruction was conducted twice weekly, for four weeks, comprising a total of eight sessions of intervention. Then respectively one week following the intervention and two months following the intervention, the pragmatic awareness test was administered to the participants. Each of the three times the test was administered, the 12 scenarios and four choices were randomly ordered to reduce the potential of a memory effect (Matsumura, 2001; 2003; 2007). During the data collection period, the test was also administered once to the native British participants at their workplace, with their managers' permission. 


\subsection{Data Analysis}

In order to score language learners' performance, native English speakers' responses were tallied and placed from the most to the least preferred choices in each scenario. In cases where a response from a language learner corresponded to that thought by the majority of native speakers to be most appropriate, the language learner received four points. Conversely, when a language learner chose the response that the least number of native speakers thought was appropriate, the language learner received only one point (Matsumura, 2001; 2003; 2007). Since twelve scenarios were included in the test, scores varied from 12 to 48, unless the language learner left questions unanswered.

To assess the effect of pragmatic consciousness-raising instruction in short-term and its long-term retention, the mean score for language learners' performance on each test was measured. The mean scores were then compared using repeated measures analysis of variance (ANOVA), in which one group of individuals participates in all of the different treatment conditions (Gravetter \& Wallnau, 2013), to evaluate the significance of mean differences among the three sample means being compared. A significance value of above $0.05(\mathrm{P}>0.05)$ does not indicate a significant difference among the mean scores for the three treatment conditions. However, a significant value of less than or equal to 0.05 ( $p \leq 0.05$ ) indicates a significant difference somewhere among the mean scores (Pallant, 2013).

To measure how much of the total variability is explained by the differences between treatments, the effect size was computed. The most common method for measuring effect size with repeated measures analysis of variance (ANOVA) is to compute the percentage of variance which is commonly identified as $\eta^{2}$ (partial eta squared) (Gravetter \& Wallnau, 2013). The guidelines to interpret the results of partial eta squared, proposed by Cohen (1988), has been presented in table 1. To determine which pairs of mean scores (if any) are significantly different, the post hoc analysis was run. The most common post hoc test for repeated measures ANOVA is Bonferroni.

Table 1. Interpretation of Partial Eta Squared $\left(n^{2}\right)$

\begin{tabular}{|l|l|}
\hline Partial Eta Squared $\left(\eta^{2}\right)$ & Effect Size \\
\hline 0.01 & Small Effect \\
\hline 0.06 & Moderate Effect \\
\hline 0.14 & Large Effect \\
\hline
\end{tabular}

\section{Findings and Discussion}

\subsection{Findings}

Table 2 presents the descriptive statistics for pre-test, post-test, and follow-up test. Descriptive statistics presented in the table consists of the mean score obtained for language 
learners' performance on each test, the standard deviation of the scores obtained on each test, and the number of language learners who took each test. The most important statistic to be considered is the mean score. According to the table, the mean scores obtained for pre-test, post-test, and follow-up test were respectively $27.50,37.58$, and 32.50 . The mean scores show that language learners experienced an increase in their performance on the post-test and then a decline on their performance on the follow-up test. However, the mean score does not show whether the difference in performance is big enough to be considered significant. In this respect, the results of multivariate tests need to be considered.

Table 2. Descriptive Statistics

\begin{tabular}{|l|c|c|c|}
\hline Tests & Mean & Std. Deviation & N \\
\hline Pre-test & 27.50 & 5.68 & 60 \\
\hline Post-test & 37.58 & 5.23 & 60 \\
\hline Follow-up test & 32.50 & 4.80 & 60 \\
\hline
\end{tabular}

Table 3 presents the results of the multivariate tests. Multivariate tests consist of Pillai's Trace, Wilks' Lambda, Hotelling's Trace, and Roy's Largest Root. All of the multivariate tests produce the same result, but the most commonly reported statistic is Wilks' Lambda (Pallant, 2013). In this study, the value obtained for Wilks' Lambda is 0.011 , with a significance value of 0.000 which is less than the cut-off of $0.05(\mathrm{p}<0.05)$. Therefore, we can conclude that the difference among the mean scores obtained from language learners' performance on pre-test, post-test, and follow-up test is significant. However, significance value does not show how big the difference is. To determine the magnitude of difference, the effect size needs to be considered. 
Table 3. Multivariate Tests ${ }^{\mathrm{a}}$

\begin{tabular}{|c|c|c|c|c|c|c|c|}
\hline \multicolumn{2}{|c|}{ Effect } & \multirow{2}{*}{$\begin{array}{l}\text { Value } \\
0.989 \\
\end{array}$} & \multirow{2}{*}{$\begin{array}{c}\mathrm{F} \\
2570.630^{\mathrm{b}}\end{array}$} & \multirow{2}{*}{$\begin{array}{c}\begin{array}{c}\text { Hypothesis } \\
\text { df }\end{array} \\
2.000\end{array}$} & \multirow{2}{*}{$\begin{array}{c}\begin{array}{c}\text { Error } \\
\text { df }\end{array} \\
58.000 \\
\end{array}$} & \multirow{2}{*}{$\begin{array}{l}\text { Sig. } \\
0.000 \\
\end{array}$} & \multirow{2}{*}{$\begin{array}{c}\text { Partial } \\
\text { Eta } \\
\text { Squared } \\
0.989\end{array}$} \\
\hline \multirow{4}{*}{ Test } & Pillai's Trace & & & & & & \\
\hline & Wilks' Lambda & 0.011 & $2570.630^{\mathrm{b}}$ & 2.000 & 58.000 & 0.000 & 0.989 \\
\hline & Hotelling's Trace & 88.642 & $2570.630^{\mathrm{b}}$ & 2.000 & 58.000 & 0.000 & 0.989 \\
\hline & Roy's Largest Root & 88.642 & $2570.630^{\mathrm{b}}$ & 2.000 & 58.000 & 0.000 & 0.989 \\
\hline
\end{tabular}

a. Design: Intercept

Within Subjects Design: Test

b. Exact statistic

Referring back to Table 3 shows that the results of the effect size measured through partial eta squared is 0.99 which, according to the guidelines set by Cohen (1988), indicates a very large effect size, that is, the difference among the performance of language learners on pre-test, post-test, and follow-up test was very large. However, significance value and effect size merely show significance of difference among the mean scores and the magnitude of difference. They do not show which tests are significantly different from each other. To determine where the difference exactly is, the results of the post hoc test need to be considered.

Table 4 presents the results of the post hoc test. The asterisk $\left(^{*}\right)$ down the column titled "Mean Difference" indicates that the difference between the mean scores obtained for the two tests being compared is significant. As the results show, there is a significant difference between the mean scores obtained for pre-test and post-test, pre-test and follow-up test, and post-test and follow-up test. In other words, language learners' performance was significantly different on each administration of the test. With respect to the mean scores obtained through language learners' performance on each test, presented in Table 2, language learners experienced a significant increase in awareness of target language pragmatic features by the end of pragmatic instruction and then experienced a significant decline in awareness of target language pragmatic features two months following pragmatic instruction. 
Table 4. Pairwise Comparisons

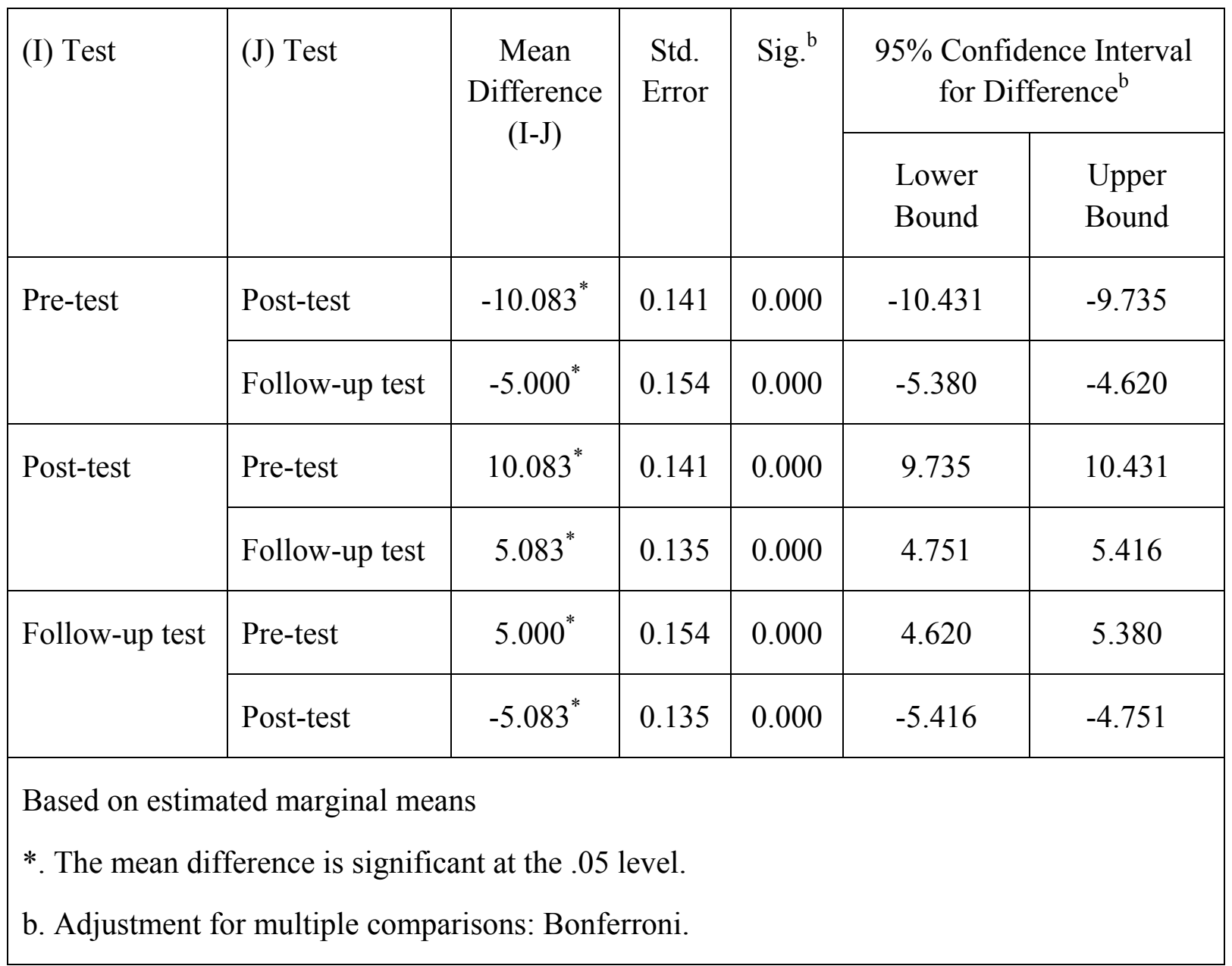

\subsection{Discussion}

The study examined the effect of pragmatic instruction on the development and sustainability of pragmatic awareness in Iranian learners of English as a Foreign Language. The results of the study revealed that pragmatic instruction has a considerable effect on the development but not sustainability of pragmatic awareness in language learners. The eight-session awareness-raising intervention conducted in the current study helped language learners to experience a marked increase in their awareness of target language pragmatic features. However, this improvement declined considerably over a period of two months following the pragmatic instruction.

These findings confirm the first hypothesis which states pragmatic instruction has a significant effect on the development of pragmatic awareness in language learners. However, the findings reject the second hypothesis which states pragmatic instruction has a significant effect on the sustainability of pragmatic awareness in language learners. These findings are consistent with the findings obtained by Matsumura (2001, 2003) and Schauer (2006) who found that target language exposure has a positive impact on the development of pragmatic awareness in language learners. These findings are also in line with the findings obtained by Matsumura (2007) who found that language learners' obtained pragmatic awareness 
gradually diverged from that of native speakers of English over time.

There are two factors which might have most probably contributed to these findings. First of all, language learners in the study were in a foreign language context. Thus, the fact that in a foreign language context, language learners are deprived from continuous and first-hand exposure to the sociolinguistic and sociocultural aspects of the target language to develop their target language pragmatic competence (Martinez-Flor, 2008; Neddar, 2012) should not be ignored. Therefore; although pragmatic instruction provided a virtual environment for language learners to be exposed to target language pragmatic features and consequently develop their pragmatic awareness, language learners did not have the opportunity to be exposed to target language pragmatic features following intervention to help sustain their pragmatic awareness.

The other factor can be attributed to the type and intensity of instruction. Language learners in the current study received pragmatic instruction for a limited period of four weeks which can be too short to lead to the sustainability of acquired knowledge. Furthermore, the study only adopted the explicit form of instruction using metapragmatic explanation of target language sociolinguistic and sociocultural features which might lead to immediate gains but might not be as effective as implicit techniques of pragmatic instruction for long-term retention. Therefore, it is suggested to include both implicit and explicit techniques of teaching target language pragmatic features and extend intervention for a longer period of time for future studies on the development of target language pragmatic awareness.

\section{Conclusion}

The study found that pragmatic instruction leads to the development but not sustainability of pragmatic awareness in learners of English as a Foreign Language. Language learners in the study managed to improve their awareness of the target language pragmatic features to a great extent by the end of pragmatic instruction. However, these gains began to disappear over time following the pragmatic instruction. Therefore, language teachers in English as Foreign Language contexts are suggested to provide opportunities for foreign language learners to be continuously exposed to target language pragmatic features through media and social networks along with the inclusion of pragmatic instructions in the foreign language classrooms.

\section{Acknowledgement}

This manuscript is dedicated to Hasti Rafieyan whose sincere encouragement paved the way to the successful accomplishment of the research study.

\section{References}

Alcón Soler, E., \& Safont Jorda, M. P. (2008). Pragmatic Awareness in Second Language Acquisition. In J. Cenoz \& N. H. Hornberger (Eds.), Encyclopedia of Language and Education Vol. 6: Knowledge about Language (pp. 193-204). Berlin: Springer.

Al-Falasi, H. (2007). Just Say "Thank You": A Study of Compliment Responses. The Linguistic Journal, 2(1), 28-42. 
Bardovi-Harlig, K. (1999). Exploring the Interlanguage of Interlanguage Pragmatics: A Research Agenda for Acquisitional Pragmatics. Language Learning, 49(4), 677-713. http://dx.doi.org/10.1111/0023-8333.00105

Bardovi-Harlig, K., \& Dornyei, B. (1998). Do Language Learners Recognize Pragmatic Violations? Pragmatic versus Grammatical Awareness in Instructed L2 Learning. TESOL Quarterly, 32(2), 233-259. http://dx.doi.org/10.2307/3587583

Bella, S. (2012). Pragmatic Awareness in a Second Language Setting: The Case of L2 Learners of Greek. Multilingua, 31(1), 1-33.

Cohen, J. A. (1988). Statistical Power Analysis for the Behavioral Sciences. Hillsdale, NJ: Lawrence Erlbaum Associates.

Farashaiyan, A., \& Tan, K. H. (2012). On the Relationship between Pragmatic Knowledge and Language Proficiency among Iranian Male and Female Undergraduate EFL Learners. The Southeast Asian Journal of English Language Studies, 18(1), 33-46.

Gravetter, F. J., \& Wallnau, L. B. (2013). Statistics for the Behavioral Sciences. Belmont, CA: Wadsworth Publishing.

Jung, J. Y. (2001). Issues in Acquisitional Pragmatics. Working paper in TESOL and applied linguistics, Teacher's College, Columbia University.

Kasper, G. (1997). Can Pragmatic Competence Be Taught? (NFLRC Network No. 6). Honolulu: Second Language Teaching \& Curriculum Center, University of Hawaii.

Kasper, G., \& Rose, K. (2002). The Role of Instruction in Learning Second Language Pragmatics. Language Learning, 52(Supplement 1), 237-273. http://dx.doi.org/10.1111/j.1467-1770.2002.tb00028.x

Kasper, G., \& Schmidt, R. W. (1996). Developmental Issues in Interlanguage Pragmatics. Studies in Second Language Acquisition, 18(2), 149-169. http://dx.doi.org/10.1017/S0272263100014868

Martinez-Flor, A. (2008). The Effects of an Inductive-Deductive Teaching Approach to Develop Learners' Use of Request Modifiers in the EFL Classroom. In E. Alcon-Soler (Ed.), Learning How to Request in an Instructed Language Learning Context (pp. 191-225). Bern: Peter Lang.

Matsumura, S. (2001). Learning the Rules for Offering Advice: A Quantitative Approach to Second Language Socialization. Language Learning, 51(4), 635-679. http://dx.doi.org/10.1111/0023-8333.00170

Matsumura, S. (2003). Modelling the Relationships among Interlanguage Pragmatic Development, L2 Proficiency, and Exposure to L2. Applied Linguistics, 24(4), 465-491. http://dx.doi.org/10.1093/applin/24.4.465

Matsumura, S. (2007). Exploring the Aftereffects of Study Abroad on Interlanguage Pragmatic Development. Intercultural Pragmatics, 4(2), 167-192. 
http://dx.doi.org/10.1515/IP.2007.010

Neddar, B. A. (2012). Short Notes on Discourse, Interlanguage Pragmatics and EFL Teaching: Where Do We Stand? Procedia - Social and Behavioral Sciences, 46, 5687-5692. http://dx.doi.org/10.1016/j.sbspro.2012.06.498

Nguyen, M. T. T. (2011). Learning to Communicate in a Globalized World: To What Extent Do School Textbooks Facilitate the Development of Intercultural Pragmatic Competence? RELC Journal, 42(1), 17-30. http://dx.doi.org/10.1177/0033688210390265

Pallant, J. (2013). SPSS Survival Manual: A Step by Step Guide to Data Analysis Using SPSS Program (5th ed.). Australia: Allen \& Unwin.

Richards, J. C. (2005). The Role of Textbooks in a Language Program. Available at http://www.professorjackrichards.com/articles/

Rose, K. R. (2000). An Explanatory Cross-Sectional Study of Interlanguage Pragmatic Development. Studies in Second Language Acquisition, 22(1), 27-67. http://dx.doi.org/10.1017/S0272263100001029

Safont Jorda, M. P. (2005). Third Language Learners: Pragmatic Production and Awareness. Clevedon: Multilingual Matters.

Saslow, J., \& Ascher, A. (2010) Top Notch 2. White Plains, NY: Pearson Education.

Schauer, G. (2006). Pragmatic Awareness in ESL and EFL Contexts: Contrast and Development. Language Learning 269-318. http://dx.doi.org/10.1111/j.0023-8333.2006.00348.x

Takahashi, S. (2005). Noticing in Task Performance and Learning Outcomes: A Qualitative Analysis of Instructional Effects in Interlanguage Pragmatics. System, 33(3), 437-461. http://dx.doi.org/10.1016/j.system.2005.06.006

Vellenga, H. (2004). Learning Pragmatics from ESL and EFL Textbooks: How Likely? Teaching English as a Second or Foreign Language 8(2), 1-13. 